\title{
RECOMENDAÇÕES DE GESTÃO DOS RECIFES ARTIFICIAIS PARA A PRÁTICA DO SURFE
}

\author{
${ }^{1}$ Marco Antonio Moraes Ocke
}

\section{RESUMO}

Os recifes artificiais são estruturas afundadas em ambiente marinho a fim de oferecer múltiplos usos e beneficiar um grande número de usuários. Entretanto, sua capacidade de propiciar melhores condições de surfe tem sido a principal característica atrativa para experiências já realizadas em alguns países do mundo. Neste contexto, esta pesquisa tem o objetivo de apresentar um conjunto de recomendações que possam contribuir com gestores públicos e privados que planejam incluir a implantação de recifes artificiais tendo como foco a melhoria nas condições de surfe em suas localidades. Para tanto, esta pesquisa qualitativa exploratória se desenvolve a partir de breve revisão teórica sobre o tema e de um estudo de casos múltiplos - Austrália, Estados Unidos, Nova Zelândia, India e Inglaterra - para sustentar o raciocínio. Os resultados incluem o caráter inovador deste tipo de estrutura demandando um aprimoramento nos métodos de construção e gestão, programas de monitoramento de longo prazo para avaliação de eficácia, desafios na integração de usuários, participação pública nas diferentes etapas do processo, gestão das expectativas dos mercados envolvidos. Uma vez que poucos estudos referentes ao tema foram desenvolvidos até o presente momento, as análises presentes neste trabalho podem contribuir com o preenchimento desta lacuna no conhecimento.

Palavras-chave: Recifes Artificiais, Surfe, Recomendações

\section{MANAGEMENT RECOMMENDATIONS OF ARTIFICIAL REEFS FOR PRACTICE OF SURFING}

\begin{abstract}
Artificial reefs are solid structures sunk in the marine environment in order to provide multiple uses and benefits for a large number of potential users. However, their ability to provide best surfing conditions has been the main attractive feature for experiments already carried out in some countries. In this context, this study aims to present a set of recommendations that may contribute to public and private managers who plan to include the deployment of artificial reefs focusing on surfing conditions improvement in many localities. Therefore, this exploratory qualitative research runs from a brief literature review on the subject and a multiple case study - Australia, USA, New Zealand, India and England - to support the reasoning. The results included the innovative nature of this type of structure, requiring a steady improvement in the construction and management methods, long-term monitoring programs to assess effectiveness, challenges in integrating users, public participation in different stages along the process, appropriate expectations management of the shareholders. Since few studies on the topic have been developed to date, the analyses presented in this study may contribute to fill in this knowledge need.
\end{abstract}

Keywords: Artificial Reefs, Surf, Recommendations.

\footnotetext{
${ }^{1}$ Doutor em Administração e Marketing pela Universidade de São Paulo, FEA - USP.

Professor Universitário, Pesquisador e Consultor em Administração, Marketing e Comunicação.

E-mail: marcoocke@hotmail.com
} 


\section{INTRODUÇÃO}

Os recifes artificiais multifuncionais são estruturas sólidas afundadas em ambiente marinho para atuar na recuperação de áreas degradadas na zona costeira como forma de combater a erosão da faixa litorânea, entretanto, a potencialidade deste tipo de estrutura representa um novo conceito de engenharia costeira a fim de propiciar múltiplos usos e beneficiar um maior número de usuários potenciais. Embora o recife artificial possa favorecer múltiplos usos, sua capacidade de propiciar melhores condições de surfe tem sido a principal característica atrativa para experiências já realizadas mundialmente (Hiliau \& Philips, 2003; Lazarow \& Blackwell, 2007; Ten Voorde et al., 2009; Simioni \& Esteves, 2010). Desde a implantação da primeira estrutura no estado da Califórnia nos Estados Unidos em 1999, diferentes tecnologias e projetos foram desenvolvidos e hoje pode ser encontrado um total de sete recifes artificiais multifuncionais no mundo, sendo dois na Nova

\section{REVISÃO TEÓRICA}

Por se tratar de um conceito recente, a literatura sobre o tema é limitada, sendo em sua grande parte produzida por profissionais ligados às companhias que projetaram ou construíram os recifes artificiais multifuncionais. Segundo os desenvolvedores do conceito, seu vetor de atratividade está na convergência dos principais benefícios gerados: (I) proteção costeira através do aumento da largura da praia adjacente ao recife; (II) melhores condições de ondas para a prática do surfe; (III) aumento da biodiversidade e biomassa de organismos pela criação de habitats marinhos (Mead \& Black, 2002; Hiliau \& Philips, 2003; Ten Voorde et al., 2009; JACKSON et al., 2012).

Embora a estrutura possa propiciar múltiplos usos e beneficiar um maior número de usuários potenciais, sua capacidade de refração da onda concentrando sua energia em um ponto, aumentando sua altura e favorecendo sua consequente rebentação tem sido seu principal aspecto de relevância (Hiliau \& Philips, 2003; Lazarow \& Blackwell, 2007; Ten Voorde et al., 2009; Simioni \& Esteves, 2010). Isto significa que sua capacidade de propiciar melhores condições de surfe é seu principal atributo. Devido à natureza inovadora do recife artificial multifuncional, tanto no projeto quanto na construção, programas de monitoramento de longo prazo foram planejados e seus resultados foram publicados em periódicos e congressos específicos (Jackson et al., 2005; Jackson et al., 2007.; Jackson \& Corbett, 2007; Jackson et al., 2012; Blacka et al., 2007; Santos \& Passavante, 2007; Simioni \& Esteves, 2010).
Zelândia; dois na Austrália; um na Índia; um na Inglaterra.

Neste contexto, esta pesquisa tem o objetivo de apresentar um conjunto de recomendações que possam contribuir com localidades que planejam incluir a implantação de recifes artificiais multifuncionais em sua área costeira, tendo como foco a melhoria nas condições de surfe nas localidades selecionadas. Uma vez que poucos estudos referentes ao tema foram desenvolvidos até o presente momento, as análises presentes neste trabalho podem contribuir com o preenchimento desta lacuna no conhecimento. Para tanto, esta pesquisa qualitativa exploratória se desenvolve a partir de breve revisão teórica sobre o tema seguida de um estudo de casos múltiplos para sustentar o raciocínio. Ao final são apresentadas as conclusões e recomendações que visam atender o objetivo proposto.

O conceito de recifes artificiais multifuncionais usando areia local para preenchimento de geocontainers é considerado um protótipo para a concepção para futuros projetos de proteção costeira e melhoria na qualidade de surfe. A operação consiste da pré-fabricação de containers de manta geotêxtil de alta durabilidade, com métodos de costura para entrada e saída de bombas e que possa ser preenchido acima do nível da água para evitar a necessidade de trabalho submarino (Mead \& Black, 2007). Para Hiliau e Phillips (2003), o uso de geocontainers oferece uma série de vantagens em relação a outros tipos de materiais de construção de recifes artificiais. Em primeiro lugar, o uso de areia disponível no local reduz a complexidade logística de transporte de materiais para o local de recife e em caso de danos ou vazamentos, o uso de areia local tem um efeito mínimo sobre o meio ambiente. Em segundo lugar, por serem mais suaves do que outros tipos de materiais, os geocontainers são mais fáceis de remover e não oferecem perigo aos usuários.

Mead e Black (2002) reforçam estas vantagens e afirmam que a utilização de geocontainers implica um custo $50 \%$ menor em relação a utilização e transporte de estruturas semelhantes compostas por rochas, que causam também um impacto negativo no tráfego de veículos e emissão de gases poluentes, além da impossibilidade de remoção da estrutura em caso de falhas ou danos ambientais. Apesar de apresentar vantagens em relação a outros tipos de estruturas, reconhece-se ainda que o estado da arte no que se refere ao design de recifes artificiais 
multifuncionais necessita de maior desenvolvimento (Jackson et al., 2012).

Conforme indicado por Blacka et al. (2007), os projetos de implantação de recifes artificiais vêm ganhando força ao redor do mundo. Países como Portugal, Estados Unidos e Brasil, têm desenvolvido estudos de viabilidade para averiguar a possibilidade de implantação de recifes artificiais para a criação de condições de surfe de qualidade. Neste cenário, é importante enfatizar que apesar de um número expressivo de lugares em diversos continentes ter implantado tais estruturas, estudos independentes analisando o desempenho dos recifes artificiais multifuncionais nas suas diferentes funções e seus impactos ambientais, sociais e econômicos são praticamente inexistentes (Ocke, 2015). Isto significa que mesmo com a falta de estudos conclusivos de retorno sobre o investimento, a compreensão da possibilidade de desenvolver uma estrutura capaz de controlar a erosão costeira mantendo a estética agradável da faixa litorânea ao mesmo tempo em que proporciona oportunidades de esporte, lazer e atração de investimentos diretos e indiretos é suficiente para que um número expressivo de localidades tenha demonstrado interesse em adotar o recife artificial multifuncional.

\section{METODOLOGIA}

Para Yin (2010), estudo de caso é uma entre diversas formas de se fazer pesquisa nas ciências sociais. Em um contexto abrangente, os estudos de casos são as estratégias mais adequadas quando o investigador tem pouco controle sobre eventos, e quando o foco se concentra em um fenômeno contemporâneo dentro de um contexto de vida real. Ainda, não se restringe a ser apenas uma técnica de coleta de dados, mas compreende uma estratégia de investigação ampla, abrangendo a lógica do projeto, as técnicas de coleta de dados e as abordagens específicas para a análise de dados (Stoecker, 1991). Para Yin (2010) o estudo de caso utiliza o raciocínio indutivo, que generalizações surgem a partir da análise de dados particulares, buscando encontrar novas relações entre elementos e fenômenos. Ainda, o estudo se concentra em uma situação, acontecimento, programa ou fenômeno particular, proporcionando assim uma excelente via de análise prática de situações da vida real. Yin (2010) afirma ainda que o estudo de caso possui características descritivas detalhadas de um assunto submetido à investigação e auxilia na compreensão daquilo que está submetido à análise, formando parte de seus objetivos a obtenção de novas interpretações e perspectivas, assim como o descobrimento de novos significados e visões antes despercebidas.
Entre os projetos de estudo de caso, são importantes dois pares principais (Yin, 2010). O primeiro par de categorias consiste em projetos de caso único e casos múltiplos. O segundo par, baseia-se na(s) unidade(s) de análise que deve(m) ser estudada(s), e faz uma distinção entre projetos de estudo de casos múltiplos, sendo o projeto de casos múltiplos holísticos em que unidade única de análise e projeto de casos múltiplos incorporados em que há unidades múltiplas de análise. Desta forma, esta pesquisa utiliza o projeto de casos múltiplos incorporado, adequado a este estudo, uma vez que envolve subunidades de análise. Ainda, a coleta de dados ocorre a partir de duas técnicas principais: documentação e entrevista.

Conforme explica a própria designação, a análise documental compreende a identificação, a verificação e apreciação de documentos para determinado fim (Moreira, 2008). Yin (2010) indica que as fontes da análise documental, frequentemente, são de origem secundária, ou seja, constituem conhecimento, dados, informação já reunidos ou organizados. No caso da pesquisa científica, a análise documental é ao mesmo tempo método e técnica. Método porque pressupõe o ângulo escolhido como base de investigação e técnica por ser um recurso que complementa outras formas de obtenção de dados, como a entrevista e o questionário. Para Moreira (2008), a análise documental é, na maioria das vezes, qualitativa e verifica o teor, o conteúdo do material selecionado para a análise. Yin (2010) indica que as fontes da análise documental, frequentemente, são de origem secundária, ou seja, constituem conhecimento, dados, informação já reunidos ou organizados. São fontes secundárias a mídia (impressa, eletrônica e digital) e relatórios técnicos.

A entrevista em profundidade é um recurso metodológico que busca, com base em teorias e pressupostos definidos pelo investigador, recolher respostas a partir da experiência subjetiva de uma fonte selecionada por deter informações que se deseja conhecer (Stoecker, 1991). Trata-se de uma técnica qualitativa que explora um assunto a partir da busca de informações, percepções e experiências de informantes para analisá-las e apresentá-las de forma estruturada. A partir da proposta de Selltiz et al. (1987), a entrevista em profundidade é extremamente útil para estudos exploratórios que tratam de conceitos, percepções ou visões para ampliar conceitos sobre a situação analisada. A amostra, em entrevistas em profundidade está ligada à significação e à capacidade que as fontes têm de dar informações confiáveis e relevantes sobre o tema de pesquisa. Assim, a seleção do entrevistado nesta pesquisa, o Prof $^{\circ}$ Dr $^{\circ}$ Shaw Mead, CEO da eCoast com base na Nova Zelândia e fundador da empresa ASR Amalgamates Solutions Research responsável pelo design e implantação dos recifes nos casos estudados, 
é de caráter intencional - quando o pesquisador faz a seleção por juízo particular, como conhecimento do tema ou representatividade subjetiva (Duarte, 2008).

\section{ESTUDO DE CASOS}

São analisados a seguir os resultados encontrados nos casos Austrália, Estados Unidos, Nova Zelândia, Índia e Inglaterra.

\section{Austrália}

A implantação do recife artificial multifuncional da cidade de Gold Coast em 2000 tinha como objetivo central estabilizar a zona litorânea através da ampliação de sua faixa de areia em cerca de 30 - 50 metros para acomodar a erosão causada pelas tempestades e as consequentes atividades de subida e recuo do nível do mar que alteravam a dinâmica estrutural da área. Os responsáveis pelo projeto avaliaram diferentes opções para atenuar os problemas de erosão costeira da região. Estruturas como molhes de pedras foram rejeitadas, uma vez que os gestores da cidade não queriam qualquer obra que pudesse prejudicar a estética agradável existente ou que viesse a interferir no fluxo de pedestres. Mead e Black (2002) enfatizam que o desafio envolvia também mecanismos mais eficientes de transporte de sedimentos para minimizar ao máximo quaisquer problemas de erosão e a criação de um ambiente marinho que atendesse as regulamentações ambientais e que não oferecesse quaisquer riscos aos usuários.

Além do objetivo central de proteção costeira de longo prazo, os gestores da localidade apresentaram a proposta de inclusão, como objetivo secundário, da melhoria de condições de surfe na praia de Narrowneck a fim de proporcionar efeitos multiplicadores proporcionados pelo favorecimento de atividades de lazer e recreação para residentes e visitantes, além da possibilidade de atração de investimento, eventos esportivos e publicidade para a localidade. Para Jackson et al., (2005) a inclusão desta atividade não foi surpreendente, dado que a cidade de Gold Coast tornou-se conhecida nas décadas de 1950 e 1960 a partir da imagem projetada do distrito de Surfers Paradise e dos internacionalmente reconhecidos surf spots da cidade tais como Burleigh Heads, Snapper Rocks, Kirra Point, e Greenmount. Este conjunto de praias fez parte de programas de ação de proteção costeira realizados anteriormente na região, o que contribuiu significativamente para formação de locais apropriados para a prática do surfe (Mead \& Black, 2002).
Vale destacar que anteriormente ao programa de implantação do recife de Narrowneck ao custo de cerca de AU\$ 2.8 milhões, a Austrália já havia investido na construção de um recife artificial em Cable Station, Perth, no oeste australiano em 1999. A iniciativa teve o objetivo de melhorar as condições de surfe em uma região já reconhecida por praticantes deste esporte. A escolha do local para a construção do recife levou em consideração a estabilidade da linha costeira, a freqüência, intensidade e direção de ondulações, acesso à praia e possíveis impactos ambientais (Pattiarachi, 2003). A estrutura construída foi composta de blocos de granito alocados em forma de "V" com volume total de $5.000 \mathrm{~m} 3$ e assentados sobre um recife natural, modificando a topografia do fundo. O projeto teve um custo total de AU\$1.8 milhões e foi financiado pelo governo do estado de Western Australia. (Jackson \& Corbett, 2007). Análises de dados de ondas e imagens obtidas por webcam durante 16 meses a partir da construção do recife indicaram que o desempenho em aumentar a qualidade das ondas para o surfe foi igual ou superior ao previsto no projeto, sendo identificados 178 dias em que ondas quebraram sobre o recife, sendo que em 142 dias, as ondas foram consideradas surfáveis em 1999 (Pattiarachi, 2003).

O resultado das análises e monitoramento do recife artificial multifuncional de Narrowneck demonstra que a implantação da estrutura obteve um resultado regular no que tange o favorecimento de condições apropriadas para a prática do surfe no local. Isto ocorre na medida em que tais condições ocorrem quando as variáveis do ambiente natural tais como características da ondulação, maré, correntes e ventos são favoráveis (Jackson et al., 2005;. Jackson et al., 2007; Jackson \& Corbett, 2007; Mead \& Black, 2002; Mead \& Black, 2007; Turner et al., 2004; Ten Voorde et al., 2009). Neste sentido, para os autores, mesmo com o fato da praia de Narrowneck não ter adquirido uma reputação de surf spot de qualidade, o recife artificial multifuncional provocou melhorias significativas nas condições de surfe do local.

Nos estágios iniciais de monitoramento, o desempenho das ondas foi avaliado qualitativamente por meio de observações relativas à distância percorrida e tempo de duração das ondas. Notou-se que a distância percorrida nas ondas atingiu comprimento superior ao previsto nos testes iniciais em modelos de laboratório, uma vez que a quebra das ondas sobre o recife fundiu-se com a quebra das ondas sobre os bancos de areia adjacentes (Mead \& Black, 2007). No final de 2005, o monitoramento passou a incluir a gravação e análise a partir de uma unidade de GPS acoplada aos surfistas totalizando seis horas de gravação de dados em ondas tipicamente inferiores a dois metros de altura. A análise dos dados mostra que o comprimento médio das ondas situou-se entre 150 e 200 metros, porém, as gravações registraram ondas de até 270 metros de 
comprimento. Da mesma forma, o maior tempo de duração de ondas gravado atingiu cerca de 60 segundos, embora a média tenha registrado tempos de cerca de 30 segundos (Jackson \& Corbett, 2007).

Inicialmente, a proposta de melhorar as condições de surfe na praia de Narrowneck foi supervalorizada e previa-se que o local se tornaria um dos melhores surf spots de Gold Coast (Jackson \& Corbett, 2007). Para os autores, criou-se a expectativa de que haveria uma transferência da atividade de surfe de residentes e visitantes de outras localidades dentro da própria cidade para Narrowneck. Estimavam que essa transferência não traria benefício líquido para a região, entretanto, enfatizavam que o local poderia se tornar um vetor de atratividade para os gestores de grandes eventos esportivos. Uma série de campeonatos de surfe local e regional foi sediada na praia de Narrowneck posteriormente a implantação do recife, porém nenhum evento de grande porte aconteceu no local (Jackson et al., 2007). Apesar disso, as já tradicionais praias de Duranbah e Snapper Rocks continuam a sediar a primeira etapa do circuito mundial de surfe profissional, além de campeonatos internacionais e regionais.

Para Mead e Black (2002), a praia não ganhou uma reputação de surf spot de qualidade pelo fato de Narrowneck estar cercada por inúmeros pontos onde a prática de surfe é considerada excelente, portanto, dentro de um cenário de alta competitividade. Além disso, os autores enfatizam que quando as variáveis de ondulação, ventos e maré estão favoráveis em Narrowneck, os outros pontos de surfe também apresentam boas condições. Jackson e Corbett (2007) complementam que o fato de o recife estar localizado a 300 metros da faixa de areia, para atuar de forma eficiente na proteção costeira, contribuiu para a baixa popularidade do local junto à comunidade do surfe que está habituada a zonas de arrebentação bem mais próximas. Ainda, autores que estudam os impactos da estrutura enfatizam que houve uma grande expectativa em relação à criação de uma onda de altíssima qualidade ao mesmo tempo que a mídia especializada criticava o desempenho do recife artificial mesmo antes de sua construção, gerando uma percepção negativa junto à comunidade (Jackson et al., 2007; Jackson \& Corbett, 2007; Mead \& Black, 2007; Blacka et al., 2007).

\section{Estados Unidos}

O recife artificial de Pratte's Reef implantado na praia de El Segundo na Califórnia teve como objetivo central recuperar a qualidade do surfe que fora alterada em função da presença de um molhe de pedras construído por uma refinaria de petróleo da empresa Chevron situada em frente à praia. Nota-se neste projeto que o recife foi construído sem participação direta de governos locais, mas com a iniciativa partindo da organização não governamental Surfrider Foundation e com financiamento custeado pela empresa petroleira que doou cerca de US\$300.000 para a construção do primeiro recife artificial para surfe dos Estados Unidos (Surfrider Foundation, 2015).

Para Simioni e Esteves (2010), não há indícios de objeção por parte da comunidade devido ao fato de o local ser utilizado predominantemente por surfistas, de forma que a construção da estrutura não afetaria atividades desenvolvidas por outros usuários. Na sua implantação foram utilizados geocontainers de tecnologia inferior à utilizada em Narrowneck, sendo que o seu volume de $1.600 \mathrm{~m} 3,40$ vezes menor do que o de Narrowneck, foi considerado pequeno para ter influência na melhoria da qualidade de ondas. Como consequência, após seis anos de monitoramento o recife foi considerado insatisfatório no atendimento de seu objetivo e acabou sendo removido no final de 2008.

Em resposta ao estudo de viabilidade realizado para o Condado de Brevard na Flórida, intitulado Feasibility Study of Multi-Purpose Artificial Surf Reefs for Brevard County, Florida (Economic Segment), o diretor ambiental da Surfrider Foundation, Chad Nelsen, aponta para um aumento no número de visitantes apenas nos primeiros meses após a implantação do recife e esclarece que o valor pago pela empresa petroleira Chevron foi insuficiente para custear um projeto que pudesse realmente recuperar os danos causados às condições de surfe naquele ponto. Porém, o fato de uma empresa ter sido responsabilizada por interferir negativamente no ambiente e ter arcado com o passivo ambiental através da construção do recife artificial, foi considerada uma ação importante para a localidade (Borrero \& Nelsen, 2003).

\section{Nova Zelândia}

De acordo com Rennie e Makgill (2003), na Nova Zelândia as áreas costeiras são consideradas públicas em que todos têm direito de acesso e uso. Assim, a ocupação mais permanente, como a construção de recifes artificiais, requer autorização das autoridades competentes. A autorização para a construção do recife artificial multifuncional de Mount Maunganui na região de Bay of Plenty na ilha norte do país foi solicitada em 1998 e autorizada em 2000 sem passar pelo processo de notificação por não existir previsões sobre os níveis de impactos gerados. Rennie e Makgill (2003) relatam que a decisão foi contestada por residentes que alegavam a presença de um recife artificial poderia atrair visitantes cujo comportamento 
seria indesejável para a comunidade local, incluindo a possibilidade de aumento de atos de vandalismo, falta de estacionamento decorrente do aumento de visitantes e impactos ambientais na vegetação e nas dunas.

Após examinar o estudo de impactos ambientais preparado pela companhia ASR e pela Universidade de Waikato, a Corte Superior manteve a decisão em favor do Conselho de Bay of Plenty no ano de 2002. A decisão levou em consideração o fato da companhia ASR ter realizado consulta de opinião pública sobre o projeto de construção do recife que consistiu em reuniões abertas com mais de 100 residentes e a obtenção de assinaturas de aprovação de representantes da população, do Departamento de Conservação e da comunidade do surfe.

A construção do recife artificial de Mount Maunganui teve início em novembro de 2005 e conclusão em junho de 2008, tendo sido utilizados geocontainers preenchidos com areia atingindo um volume total de $6.500 \mathrm{~m} 3$. Atrasos na conclusão da obra ocorreram por dificuldades em recolher fundos para cobrir o aumento do custo do projeto que passou de NZ\$500.000 estimados originalmente para NZ\$1.5 milhões (Jackson \& Corbett, 2007). Há poucos relatórios de monitoramento avaliando a qualidade das ondas sobre o recife, e sua efetividade quanto a este aspecto gera debate. A empresa ASR que concluiu a obra, baseada em imagens obtidas por surfistas locais e sites de surfe, aponta evidências de que o recife melhorou a qualidade de ondas, também quando as demais variáveis são favoráveis. Nota-se neste ponto que o que acontece em Mount Maunganui replica parcialmente os resultados obtidos em Narrowneck, onde as expectativas geradas superam a capacidade de entrega de valor da estrutura. Em contrapartida, Simioni e Esteves (2010) indicam que a praia onde o recife foi implantado vem recebendo críticas dos surfistas locais que afirmam ter encontrado boas condições de surfe poucas vezes desde a finalização da obra.

Outro caso é implantação do recife artificial multifuncional de Opunake no distrito de Taranaki na Nova Zelândia com o objetivo central de aprimorar as condições de surfe. O processo de participação pública envolveu audiências com a população e a formação de um comitê local para avaliação das propostas. A construção do recife de Opunake sofreu atrasos devido à dificuldade de implantação da estrutura gerando aumento dos custos em relação ao orçamento inicial. Em abril de 2008, NZ\$1,7 milhões haviam sido gastos para a construção do recife, e um ano depois ainda faltava arrecadar NZ\$70.000 mil para sua finalização (Simioni \& Esteves, 2010).
Um detalhado estudo de viabilidade intitulado Proposed Artificial Surf Reef, Opunake, South Taranaki: Economic and Social Impact Report desenvolvido pelo TRC - Tourism Resource Consultants no ano de 2002 indicava que a implantação do recife traria os seguintes benefícios em um período de cinco anos: retorno econômico equivalente ao dobro do custo da obra, geração de cerca de seis mil empregos e um aumento na economia na área do distrito de Taranaki da ordem de NZ\$147.500 ao ano. No estudo, os aspectos negativos potencialmente causados pela implantação do recife incluem: aumento exacerbado do número de surfistas, resultando em conflitos de uso e risco para os banhistas, atração de surfistas desempregados para a área de Opunake e a supervalorização do mercado imobiliário interferindo na dinâmica de moradores locais.

\section{Índia}

A região de Kerala no sudoeste da India é um dos mais populares destinos turísticos do sul do país desde 1930. No entanto, devido ao rápido desenvolvimento nos últimos anos, a orla da praia de Kovalam sofreu erosão grave durante as estações de monções, o que conduziu à perda de parte valiosa da faixa de areia. Para combater o problema, o departamento de turismo de Kerala passou a considerar opções de gestão tradicionais, incluindo a construção de um bloqueio rochoso, entretanto, a administração pública decidiu aplicar uma solução mais sustentável para resolução do problema de erosão sem alterar a estética da praia. Após a realização de estudos de campo, desenvolvimento de modelos numéricos e físicos, e realização de calibrações e ensaios exaustivos, a empresa ASR completou a construção do recife artificial multifuncional de Kovalam em fevereiro de 2010 (Ocke \& Ikeda, 2013).

O recife foi projetado especificamente para dissipar a rebentação de ondas que atingiam a região, minimizando assim os efeitos erosivos na praia. Além disso, o recife é posicionado para redirecionar as correntes que têm sido parcialmente responsáveis pela redução histórica do tamanho da praia de Kovalam. Relatórios de monitoramento locais mostram que o recife tem sido extremamente bem sucedido na criação de uma seção mais larga e mais estável da praia de Kovalam. De acordo com o Departamento de Turismo de Kerala, o recife tornouse uma vitrine no conceito de gestão sustentável para o turismo litorâneo, sem prejudicar o meio ambiente, o que tem estimulado o turismo na região. Neste caso, não houve grandes expectativas quanto à possibilidade de melhoria da qualidade de ondas para o surfe. Entretanto, logo após a conclusão da obra, a empresa ASR responsável pelo projeto divulgou um 
vídeo na internet registrando o resultado positivo no que tange à qualidade das ondas, atraindo a atenção de organizações ligadas à indústria do surfe que passaram a monitorar o desempenho do recife para, em conjunto com as entidades locais, maximizar seu benefício no longo prazo.

\section{Inglaterra}

A construção do recife de Boscombe na cidade de Bournemouth no sudoeste da Inglaterra teve início em julho de 2008 e foi concluída em novembro de 2009. Com o aumento da prática do surfe no país, bem como a crescente presença de grandes marcas desta indústria na Europa, o objetivo do recife artificial de Boscombe era criar melhores condições para a prática do esporte e desta forma atrair investimentos, visitantes e eventos. A implantação do recife artificial multifuncional na cidade foi desenvolvida e financiada pelo governo local e fez parte do projeto de modernização da orla, revitalização do píer de Bournemouth e um projeto de design desenvolvido para promover os atributos turísticos da cidade (Ocke \& Ikeda, 2013).

O custo total do projeto de revitalização da área foi originalmente estimado em $€ 9$ milhões, sendo o orçamento inicial do recife avaliado em cerca de $€ 1,5$ milhão, entretanto, devido a uma série de fatores, inclusive condições meteorológicas e oceanográficas desfavoráveis, o custo total da obra ultrapassou o valor estimado. O governo local angariou fundos para o projeto de revitalização através da venda de um terreno usado como área de estacionamento localizado na orla. A companhia imobiliária Barratt Homes comprou o terreno para construir um complexo residencial de 169 apartamentos, que foram vendidos posteriormente à com preços entre $£ 200.000$ e $£ 590.000$ (Daily Echo, 2012).

Em 2003, a agência Market Research Group (MRG) conduziu uma consulta pública encomendada pelo governo local onde os interessados podiam indicar através de múltipla escolha as suas prioridades ou preferências de uma lista de obras previamente selecionadas para a renovação desta parte da cidade. Dos 2.300 participantes, 89\% selecionaram a revitalização do Píer de Bournemouth, $81 \%$ votaram na melhora da iluminação e da infraestrutura da orla, $74 \%$ escolheram a construção de uma praça em estilo mediterrâneo, enquanto $59 \%$ optaram pelo recife artificial multifuncional. $\mathrm{O}$ impacto ambiental previsto foi considerado na pior hipótese como neutro, mas assim como ocorreu no caso de Mount Mauganui na Nova Zelândia, a comunidade local demonstrou preocupação com o aumento do trânsito de carros, a falta de estacionamento e o aumento exagerado de pessoas na praia, problemas já existentes durante o verão.
O estudo de Rendle e Rodwell (2014) investigou os possíveis impactos econômicos para a localidade com base no aumento do fluxo turístico. Por meio de uma avaliação preliminar composta da aplicação de questionários com 523 visitantes ao longo de um período de 32 meses entre os anos de 2009 e 2011, o estudo demonstrou que o recife artificial multifuncional inicialmente atuou como uma atração turística, porém, após os recorrentes relatos da incapacidade da estrutura entregar valor conforme proposto em seus objetivos, sua atratividade perdeu força. Entretanto, o estudo encontrou os impactos positivos do programa de revitalização da região da zona costeira, incluindo a implantação do recife artificial multifuncional, que passou a atrair a atenção de investidores com base na constante publicidade da cidade de Bournemouth. Apesar da publicidade negativa direcionada para a empresa responsável pelo projeto, estima-se que a exposição da revitalização da cidade na mídia, teria um valor aproximado de US\$ 10 milhões se investidos em propaganda tradicional (Rendle \& Rodwell, 2014).

\section{ANÁLISE DOS RESULTADOS}

As análises desta pesquisa permitem indicar uma série de recomendações para localidades que eventualmente planejem implantar o recife artificial para melhorar as condições de surfe e assim oferecer uma oferta de esporte, lazer e entretenimento de qualidade para seus usuários.

\section{a) Inovação e Tecnologia}

Os recifes artificiais podem favorecer boas condições de surfe quando as demais variáveis do ambiente natural estão apropriadas. O uso de geocontainers oferece vantagens em relação a outros tipos de materiais de construção de recifes artificiais. Contudo, este modelo é considerado um protótipo para a concepção de futuros projetos de proteção costeira e melhoria na qualidade de surfe. Assim, o estado da arte no que se refere ao design e implantação de recifes artificiais ainda necessita de maior desenvolvimento, permitindo que diferentes localidades ao redor do mundo aperfeiçoem o modelo e desenvolvam sua própria tecnologia.

Em virtude do caráter inovador do recife artificial multifuncional e pelo fato de pouco se conhecer os impactos da implantação desse tipo de estrutura no ambiente costeiro, dificilmente os governos optarão por financiar obras de proteção costeira não tradicionais. Além disso, embora o recife possa promover múltiplas atividades e desta forma ampliar as oportunidades de financiamento por meio de parcerias entre organizações públicas e privadas, o 
interesse do governo local será sempre determinante uma vez que as zonas costeiras são consideradas áreas de uso público. Portanto, quanto maior for o número de indivíduos beneficiados com a implantação dos recifes, maiores serão as chances de esta ser a estrutura escolhida para o programa de gestão costeira em detrimento a obras tradicionais.

\section{b) Estudos de Viabilidade e Protocolos de Monitoramento}

A implantação dos recifes não apresenta garantias de que os impactos sejam positivos e para sua realização deve ser considerada uma série de custos adicionais ao seu valor inicial como um orçamento para atender a futuros custos de manutenção, reparo e correção. $\mathrm{O}$ custo de remoção também deve ser considerado, no caso de a estrutura não entregar o valor proposto ou começar a se desintegrar ao longo de seu ciclo de vida. Apesar dos possíveis retornos financeiros sobre o investimento com o aumento do número de visitantes e aceleração de atividades econômicas decorrentes da implantação do recife, tal receita não deve ser considerada para arcar os custos acima mencionados.

Estudos de viabilidade e avaliações de impactos devem ser realizados para favorecer o processo de licenciamento baseado em dados científicos sólidos. É essencial que os relatórios de avaliação de impacto sejam independentes e não desenvolvidos por grupos com interesse comercial no projeto de execução. Assim, os estudos poderão analisar o desempenho potencial da estrutura, bem como sua contribuição para a economia local de forma realista, com base nas melhores informações disponíveis, evitando futuras críticas ao projeto. Ainda, sua implantação deve ser seguida por um acompanhamento de curto, médio e longo prazo, para verificar se os objetivos estão sendo alcançados e se os benefícios almejados podem, de fato, se materializar. Os protocolos de regulamentação devem incluir planos de monitoramento pré e pós-construção, critérios claros que permitam a avaliação objetiva do desempenho dos recifes artificiais multifuncionais, divulgação pública e transparente dos custos, impactos ambientais, desempenho e retorno econômico da obra.

\section{c) Participação Pública}

A participação pública na gestão costeira tem o objetivo de envolver o maior número possível de setores da comunidade tais como moradores, empresas, organizações não-governamentais, governo e universidades no processo de tomada de decisão de forma que todos se tornem igualmente responsáveis pelos resultados obtidos. Portanto, o envolvimento do público é imprescindível desde as etapas iniciais do processo de decisão, incluindo a seleção das obras, eventos ou práticas a serem contempladas nos estudos de viabilidade e de impactos.

A intenção de governos locais em subsidiar atividades que beneficiam um grupo específico deve ser justificada, pois outros grupos podem reivindicar que o investimento de dinheiro público em outras áreas poderia gerar o mesmo retorno financeiro, atendendo um número igual ou maior de pessoas. Enquanto não ficarem claros quais são os benefícios econômicos gerados pelo recife artificial e como eles serão distribuídos espacialmente, temporalmente e para quais setores da comunidade, o uso de recursos públicos para execução do programa pode ser caracterizado como uma escolha injusta. Isto fica ainda mais evidente nos casos em que a implantação da estrutura tenha como objetivo primário melhorar as condições para o surfe, pois os impactos positivos beneficiam mais diretamente determinados grupos enquanto os impactos negativos são arcados por toda a comunidade. Ainda, nota-se que os recifes artificiais multifuncionais podem tornar-se mais atrativos em áreas que já possuem uma comunidade de surfe estabelecida e onde as condições das ondas sejam regulares, com potencial para tornarem-se boas e até mesmo excelentes. Essas características aliadas à necessidade do governo em estimular a economia local, fazem com que a tomada de decisão seja influenciada por grupos ou indivíduos ligados ao surfe e à exploração comercial do esporte.

\section{d) Visitantes e Residentes}

Considerando que a implantação dos recifes atraia um maior número de visitantes, pode-se supor que o aumento no fluxo de pessoas na localidade venha a trazer conflitos entre os usuários, principalmente entre residentes e visitantes. As recomendações incluem estimular a criação de áreas de lazer e dar suporte ao empreendedorismo local para expansão dos negócios, visando atender ao maior número de usuários do ambiente. Ressalva-se a importância de se manter as culturas tradicionais locais e evitar a pressão excessiva da atividade turística resultando em aumento no trânsito de veículos, falta de estacionamentos e o número exagerado de pessoas na praia. Em regiões onde o turismo já está consolidado, atividades que venham atrair visitantes nos períodos de menor movimento turístico são mais interessantes e beneficiam de forma mais direta a população e a economia local combatendo o fenômeno da sazonalidade. Por outro lado, nas regiões onde o turismo ainda é pouco desenvolvido, a implantação dos recifes traz consigo a necessidade de estudos de planejamento turístico adequados para evitar a degradação de áreas naturais pouco exploradas. 


\section{e) Gestão de Expectativas}

A gestão de expectativas é fundamental para manter a percepção positiva das comunidades envolvidas diretamente na implantação de recifes artificiais e ao mesmo tempo evitar expectativas irreais sobre o eventual desempenho da estrutura. Esse aspecto se torna ainda mais evidente quando o objetivo primário do projeto é o favorecimento das condições de surfe, uma vez que há um desalinhamento entre a expectativa da comunidade do surfe e as condições de ondas que podem ser geradas. O desenvolvimento de recifes artificiais com foco no aprimoramento das condições de surfe encontra-se em seus estágios iniciais, portanto, mais atenção e pesquisas são necessárias antes que a estrutura possa ser considerada totalmente confiável.

Especula-se que a implantação de recifes artificiais multifuncionais possa agregar valor às propriedades nas imediações do local proporcionando benefícios residenciais sob a forma de valorização de imóveis, entretanto, não há dados quantitativos que possam sustentar esta argumentação. Porém, é notável que as atrações baseadas na natureza ganham importância para imagem dos lugares e, neste contexto, a implantação de recifes artificiais pode contribuir com a promoção do lugar na forma de publicidade por meio de freqüente exposição na mídia e pelo incentivo a outras localidades buscarem alternativas eficientes que não impactam negativamente a estética das praias e proporcionam vantagem competitiva à localidade.

A cobertura midiática pode produzir expectativas irreais na comunidade. A gestão cuidadosa da relação da localidade com a mídia é essencial para o sucesso do projeto aos olhos dos diferentes mercados da localidade e esta relação pode ser fortalecida por meio de comunicação informativa a fim de fornecer explicações sobre o projeto e as expectativas de

\section{REFERÊNCIAS}

Blacka, M.J.; Anderson, D.J. \& Cunningham. (2007). Analysis of Shoreline Variability, Seasonality and Erosion. Accretion Trends: February 2007 - July 2007. Report 16: Northern Gold Coast Coastal Imaging System. Water Research Laboratory Technical Report 2007/34, UNSW.

Borrero, J.C. \& Nelsen. (2003). Results of a Comprehensive Monitoring Program at Pratte's Reef. Proceedings of the 3rd International Surfing Reef Symposium. Raglan, New Zealand, 83-99. desempenho desde o início. Assim, em caso de falhas ou problemas, a transparência torna-se essencial para evitar rumores e sentimentos de decepção. Ainda, a comunicação de marketing do funcionamento do recife artificial multifuncional deve se concentrar em seu caráter inovador e experimental, evitando o apelo baseado em alegações de desempenho que não podem ser comprovadas.

\section{CONSIDERAÇÕES FINAIS}

A possibilidade de os recifes artificiais de propiciarem melhores condições de surfe tem sido a principal característica atrativa para localidades que desejam incluir a implantação desta estrutura em seus programas de gestão. A fim de avançar no conhecimento da área, este artigo apresentou um conjunto de conclusões e recomendações a fim contribuir com gestores da administração pública e da iniciativa privada no que tange a implantação de recifes artificiais tendo como foco a melhoria nas condições de surfe em suas localidades. Experiências realizadas na Austrália, Estados Unidos, Nova Zelândia, Índia e Inglaterra, apontam para o caráter inovador deste tipo de estrutura o que resulta em uma corrida tecnológica para o constante aprimoramento nos métodos de construção e gestão dos recifes artificiais. Além disso, a análise dos casos indica a necessidade de se desenvolver protocolos de monitoramento de longo prazo destas estruturas com o objetivo de avaliar sua eficácia. Nota-se também a presença de desafios de integração dos diferentes mercados envolvidos, principalmente na relação entre residentes e visitantes, a importância da participação dos públicos nas diferentes etapas dos processos de decisão e a gestão assertiva de expectativas. Poucos estudos referentes ao tema foram desenvolvidos até o presente momento, assim, as análises presentes neste artigo buscaram contribuir com o preenchimento desta lacuna no conhecimento.

Daily Echo. Boscombe: is it surfing or suffering? Disponível <http://www.bournemouthecho.co.uk/search.> Acesso em Maio 2012.

Duarte, J. (2008). Entrevista em Profundidade. In: Duarte, J. \& Barros, A. (Eds) Métodos e Técnicas de Pesquisa em Comunicação. $2^{\mathrm{a}}$ Ed. São Paulo: Atlas.

Hiliau, W. \& Philips, D. (2003). Artificial Surfing Reef Construction. Proceedings of the $3^{\text {rd }}$ International Surfing Reef Symposium. Raglan, New Zealandia. 
Jackson, L.A., Tomlinson, R.B., Turner, I., Corbett, B., Mcgrath, J. (2005). Narrowneck Reef: Results of 4 years monitoring and modifications. 4th International Surfing Reef Symposium, Los Angeles, January.

Jackson, L. \& Corbett, B. (2007). Review of existing multi-function artificial reefs. Australasian Conference on Coasts and Ports. Perth, Australia.

Jackson, L.A., Tomlinson, R.B., Turner, I., Corbett, B., Mcgrath, J. \& Stuartt, G. (2007). Narrowneck Reef: Review of 7 years of monitoring results. Shore \& Beach. American Shore \& Beach Preservation Association. v. 75, p. 67-79.

Jackson, L.A., Tomlinson, R.B.; Corbett, B. \& Strauss, D. (2012). Long term performance of a submerged coastal control structure: a case study of the Narrowneck multi-functional artificial reef. Gold Coast Shoreline Management Plan Implementation.

Lazarow, N.; Blackwell, B. (2007). Dropping In: A case study approach to understanding the socioEconomic impacts of recreational surfing and its value to the coastal economy. Shore and Beach. v. 75, n.4, p. 21-31.

Mead, S. \& Black, K. (2001). Artificial surfing reefs for erosion control and amenity: Theory and application. Journal of Coastal Research (special issue 29): p. 115-30.

Mead, S. \& Black, K. (2002). Multi-Purpose Reefs Provide Multiple Benefits. Amalgamating Coastal Protection, High-Quality Surfing Breaks and Ecological enhancement to Maximize User Benefits and Development Opportunities. South Australian Spatial Information Council Conference. Ventura, California.

Mead, S. \& Black, K. (2007). Sand bank responses to a multi-purpose reef on an exposed sandy bank. Shore \& Beach. v. 75, n.4, p. 55-66.

Moreira, S.V. (2008) Análise Documental como Método e Técnica. In: Duarte, J. \& Barros, A. (Eds) Métodos e Técnicas de Pesquisa em Comunicação. $2^{\mathrm{a}}$ Ed. São Paulo: Atlas.

Ocke, M. (2015). Marketing de Lugares: Estudo de Impactos do Recife Artificial Multifuncional. Tese de Doutorado apresentada a Faculdade de Economia, Administração e Contabilidade da Universidade de São Paulo, FEA-USP.

Ocke, M. \& Ikeda, A. A. (2003) Multipurpose artificial reefs as touristic attraction proposal in the
Brazilian coastline. Tourism Management Studies Conference, Algarve, Portugal, v. 1, p. 225-236.

Pattiarachi, C. (2003). Performance of an artificial surfing reef: Cable Station Western Australia. Proceedings of the Sixth International Conference on Coastal and Port Engineering in Developing Countries. Colombo, Sri Lanka.

Rendle, E.J. \& Rodwell, L.D. (2014). Artificial surf reefs. A preliminary assessment of the potential to enhance a coastal economy. Marine Policy, v.45, p. 349-358.

Rennie, H.G. \& Makgill, R. (2003) Implications of New Zealand's effects-based coastal planning regime for artificial surfing reefs: The Mount Reef case. Proceedings of the 3rd International Surfing Reef Symposium. Raglan, New Zealand, 260-267.

Santos, D. \& Passavante, J. (2007). Recifes Artificiais Marinhos: Modelos e Utilizações no Brasil e no Mundo. Bol. Téc. Cient. CEPENE, Tamandaré, Pernambuco, v. 15, n. 1, p. 113-124.

Selltiz, C. \& Whrightsman, L. S.; Cook, S.W. (1987). Métodos de Pesquisa nas Relações Sociais. São Paulo: EPU.

Simioni, B. \& Esteves, L. (2010). Avaliação Qualitativa do Desempenho dos Recifes Artificiais Multifuncionais (RAM). Revista de Gestão Costeira Integrada, v. 10, p. 127-145.

Stoecker, R. (1991). Evaluating and Rethinking the Case Study. The Sociological Review, v. 1, n. 39, p. $88-112$.

Surfrider Foundating - Surfrider Foundation's Artificial Surf Reef Policy. Disponível em: http://www.surfrider.org/artificialreef/areefs.asp. Acesso em Fevereiro 2015

Ten Voorde, M.; Antunes, J.S. \& Neves, M.G. (2009). Designing a Preliminary Multifunctional Artificial Reef to Protect the Portuguese Coast. Journal of Coastal Research, v.25, n.1, p.69-79.

Turner, I. L.; Aarninkhof, S. G. J.; Dronkers, T. D. T. \& Mcgrath, J. (2004). CZM application of Argus coastal imaging at the Gold Coast, Australia. Journal of Coastal Research, v. 20, p.739-752.

Yin, R. K. (2010). Estudo de Caso: planejamento e métodos. $4^{\mathrm{a}}$ Ed. Porto Alegre, Bookman. 